\title{
On-site evaluation of pancreatic lessions according to Papanicolaou Society of Pancreatobiliary Cytology, how can it contribute to diagnostic accuracy?
}

Irem Guvendir ( $\square$ iremguvendir@hotmail.com )

Health Sciences University, Umraniye Education and Research Hospital, Pathology Department, Istanbul

Itir Ebru Zemheri

Health Sciences University, Umraniye Education and Research Hospital, Pathology Department, Istanbul

Kamil Ozdil

Health Sciences University, Umraniye Education and Research Hospital, Gastroenterology Department, Istanbul

Research Article

Keywords: On-site evaluation, pancreas, cytopathology, EUS-FNA

Posted Date: February 4th, 2022

DOI: https://doi.org/10.21203/rs.3.rs-1315770/v1

License: (c) (i) This work is licensed under a Creative Commons Attribution 4.0 International License. Read Full License 


\section{Abstract}

Background: The use of ROSE in EUS-FNA pancreatic lesions is still controversial in many centers. In this study, we aimed to demonstrate the diagnostic accuracy of ROSE and its contribution to the diagnostic accuracy, as well as its assistance to the pathologist/cytopathologist.

Methods: 162 EUS-FNA biopsies were included in the study. EUS-FNA cytology results were reported according to the six-tiered system of Papanicolaou Cytopathology Society and compared to their final diagnosis with histopathology and/or clinical follow-ups regarding malignancy. In ROSE and non-ROSE patients, diagnostic ability, the difference in diagnostic accuracy, and its contribution to providing the pathologist with sufficient amount of tissue acquisition (number of slides and cell blocks) for later examination were compared.

Results: In the non-ROSE group, the diagnostic accuracy according to the final diagnoses was $96 \%$ and the sensitivity was $94.44 \%$, specificity $100 \%$, PPV 100\%, NPV $87.50 \%$; while diagnostic accuracy was $97.09 \%$, sensitivity $97.47 \%$, specificity $95.83 \%$, PPV $98.77 \%$, NPV 92\% in patients with ROSE. There was no significant difference in diagnostic accuracy between those with and without ROSE (p:0.078). In diagnostic cases, the number of passes, slides and cell blocks were significantly higher in patients with ROSE than those without ROSE (p:0.003, p:0.007, p:0.012, respectively). ROSE was independently associated with diagnostic ability when evaluated by number of passes, slides, cell blocks in regression analysis (p:0.001, OR:5.07, confidence interval: 1.89-13.5). If the lesion is solid or contains a solid component, cytological corcordance with final diagnosis is higher than cystic ones $(p<0.001)$.

Conclusion: ROSE may increase the acquisition of sufficient tissue, but it does not have an advantage in diagnostic accuracy. ROSE may raise the number of required slides, which may benefit the pathologist in making the diagnosis. If the lesion is solid and/or contains a solid component, the success of obtaining a diagnostic ability is higher in patients with ROSE than in those without. Therefore, ROSE still maintains its applicability in terms of making the final diagnosis to the patient and increasing the diagnostic efficiency.

\section{Background}

Although pancreatic cancer is the 14th most common cancer in the world, it ranks 7th in cancer deaths [1]. The reported 5 -year survival rate for pancreatic cancer patients is quite low, about $6 \%$, ranging from $2 \%$ to $9 \%$ [2]. Therefore, prompt diagnosis and early initiation of treatment of pancreatic cancers is very critical for patients.

Today, endoscopic ultrasound guided fine needle aspiration (EUS-FNA) biopsy greatly contributes to the early diagnosis of pancreatic cancers. The correct interpretation of the cytological material and the communication between the pathologist and the clinician are very important, and the Papanicolaou Society of Cytopathology in Pancreatobiliary System (PSC-PS), revised in 2014, makes significant contributions to this goal [3]. However, tissue acquisition and diagnostic accuracy under EUS guidance are affected by various factors and their influences on the diagnostic efficacy cannot be ignored. Needle type, number of needle passes, endoscopist's experience, and rapid on-site evaluation (ROSE) are some of these factors. In addition, the amount of tissue acquisition, the quality of the cytological material, and the presence of the cell block are among the other factors that help cytopathologists / pathologists-in subsequent examinations $[4,5]$.

Regarding EUS-FNA, it can be argued that especially rapid on-site evaluation (ROSE) can greatly contribute to the diagnostic efficacy, obtaining adequate tissue and to the diagnostic accuracy. As a matter of fact, the absence of ROSE has been shown to reduce the diagnostic accuracy by 10-15\% [6]. In a meta-analysis, studies with ROSE showed a higher sensitivity with a slightly higher specificity as compared with studies without ROSE [7]. However, many high- 
volume centers do not practice ROSE, since this process requires extra time and workforce [8]. It is important to reveal the power of ROSE in clinical practice and to optimize the evaluation. The number of passes, especially the number of slides and cell blocks required for adequate tissue and high diagnostic accuracy with ROSE has not been adequately studied in the literature.

Our aim in this study is 1) to show the adequacy of tissue acquisition and diagnostic accuracy 2) to show if and how ROSE contributes to this 3) to investigate the relation of the number of passes, the number of slides and the availability of cell block with ROSE to the diagnostic efficacy in EUS-FNA biopsies in pancreatic lesions.

\section{Methods}

Patients older than 18, who applied to the gastroenterology unit between 2016-2021 and underwent EUS-FNA for pancreatic lesion were evaluated retrospectively. The clinical follow-up of the patients after EUS-FNA biopsy for at least 6 months, and the histopathological diagnoses obtained by surgery or tru-cut biopsy, if any, were analyzed. Patients whose follow-up were in other centers were evaluated using nation-wide medical electronic records. Patients' oncology admissions, treatments (chemotherapy-radiotherapy regimens for pancreatic malignancy) and pathology reports, radiological work-ups, surgical follow-ups were analyzed. Patients' histopathological diagnoses obtained by surgery or tru-cut biopsy were regarded as "final histopathology". Patients who were diagnosed with pancreatic carcinoma clinically and / or histopathologically and received oncological treatment were regarded to have "malignant clinical diagnosis"

A total of 162 EUS-FNA biopsies were included in the study. All EUS procedures were performed by the same experienced gastroenterologist. EUS-FNA cytology results were reported according to the six-tiered system of Papanicolaou Cytopathology Society (PSC-PC) [3]. Reported categories were as follows; "I- non-diagnostic"; "II- benign"; "III- atypical”; "IVa- neoplastic benign”; "IVb- neoplastic other"; "V- suspicion of malignancy”; "VI- malignant”. Cytological diagnoses (malignant / non-malignant) were compared with final histopathological and/or clinical diagnoses (malignant / non-malignant). "Diagnostic ability" was defined for cases which can be diagnosed other than category I according to PSC-PS. This study was approved by the ethics committee of the University of Health Sciences Umraniye Training and Research Hospital and meets the requirements of the Declaration of Helsinki.

\section{Technique:}

All patients provided informed consent for endoscopy and EUS-FNA. The EUS-FNA was performed using $22 \mathrm{G}$ needle. (Fujinon Fujifilm, Tokyo, Japan, VP-4450 HD, EG 580 UT)

ROSE was provided by pathology residents, pathologists or cytopathology technicians present in the endoscopy unit. One or more air-dried Diff-Quick stained smear was prepared from each pass and qualification were granted. Remaining tissues were spread on slides and fixed in ethanol. The thick, white-yellowish colored biopsy material remaining at the needle tip after smears was fixed in tubes filled with $10 \%$ formaldehyde. Then the slides, which were fixed in ethanol, were stained with Papanicolaou stain in the pathology laboratory. The biopsy material was processed and embedded in paraffin blocks, 4.5-5-micron sections were taken and stained with Hematoxylin-eosin. Slides and cell block sections, were evaluated by two pathologists, immunohistochemical staining and molecular testing were performed when necessary.

\section{Statistical Analysis:}


Sensitivity, specificity, positive predictive value (PPV), negative predictive value (NPV), and diagnostic accuracy of PSCPS were calculated using cytological diagnosis as benign or malignant with the final histopathological and/or clinical diagnosis whether they are malignant or non-malignant. Non-diagnostic (category-l) cases were not included when calculating diagnostic accuracy. Based on distribution characteristics, results were expressed as mean \pm standard deviation (SD) or median with interquartile range (IQR). The comparison of qualitative variables was analyzed using the Pearson Chi-square test or Fisher exact test; Quantitative independent variables were compared using t-test and Mann Whitney $U$ test for parametric and non-parametric distributions respectively.

The results were evaluated in $95 \%$ confidence interval and statistical significance level was defined as $p<0.05$. The analyzes were performed using IBM SPSS-21 (Statistical Package for Social Sciences, Chicago, IL, USA).

\section{Results}

162 cases with known final diagnosis were evaluated. $102(62 \%)$ of the patients were male and the mean age in the whole group was 60.54 (23-86). There was no age difference between women and men $(59.7 \pm 13.3,61.8 \pm 12.9$ respectively, p:0.6). EUS characteristics of 22 lesions were purely cystic, 36 were cystic with solid components, and 104 were solid.

ROSE was available for 121 cases, while it was not performed in 41 cases. The distribution of the lesions according to the anatomical regions of the pancreas were examined; there was no significant difference between the localizations according to the cystic / solid characteristic, the size of the lesions, and whether they had ROSE. The distribution of the lesions was as follows; 33 in the uncinate, 71 in the head, 29 in the body, and 29 in the tail.

When pure solid lesions (n:104) and solid containing cystic lesions (n:36) were evaluated together and compared with pure cystic, ROSE was found to be performed significantly in favor of lesions with solid component (p:0.004). The number of passes was significantly higher in patients with ROSE compared to patients without ROSE (median: 2 , mean:1.79; 1, 1.37 respectively; p:0.004). The median number of slides was also significantly higher in patients who underwent ROSE (Table 1). In addition, the median number of cell blocks obtained in patients with ROSE was 2, while it was 1 in patients without ROSE, and it was significantly higher in patients with ROSE $(p<0.001)($ Table 1$)$.

Patients' PSC-PC results were reported as; category-I for 34 patients, cat.-II for 30, cat.-III for 18, cat.- IVa for 3, cat.-IVb for 10 , cat.-V for 11 , and cat.-VI for 56 patients (Table 2). Thirty-four of the lesions were non-diagnostic (category I) when rest (n: 128) were considered diagnostic (category: II, III, IVa, IVb, V, VI). The cases with ROSE showed higher "diagnostic ability" than those without ROSE and ROSE was related to achieving a PSC-PS result in a diagnostic category ( $\mathrm{p}$ : 0.001). Furthermore, diagnostic ability in solid lesions and in cystic lesions with a solid component was higher than in pure cystic lesions (p:0.002).

No significant difference was found between the diagnostic and non-diagnostic groups in terms of the number of passes, slides, and cell blocks (p: 0.79, 0.2, 0.09, respectively). In addition, in diagnostic cases ROSE was associated with higher number of passes, slides and cell blocks (p:0.003, p:0.007, p:0.012, respectively). ROSE was also independently associated with diagnostic ability when evaluated together with number of passes, slides, cell blocks using regression analysis (p:0.001, OR:5.07, confidence interval: 1.89-13.5).

Histopathological final diagnosis was obtained in $16 \%$ of the lesions (n:26), or determined according to the histopathological evaluation of tissue acquired from metastases, if any. Accordingly, similar to various studies in the literature: categories II and IVa were regarded as benign (negative) while category III, IVb, V, VI were accepted as significant (positive) in terms of malignancy (9). Fourteen of 26 cases with final histopathological diagnosis were 
adenocarcinoma; the rest were as follows: 2 mucinous cystic neoplasia, 1 high grade pancreatic intraepithelial neoplasia (PANIN), 1 intraductal papillary mucinous neoplasm (IPMN), 2 neuroendocrine tumor, 1 lymphoma, 1 mixed acinar neuroendocrine ductal neoplasia, and 4 were defined as consistent with chronic pancreatitis.

Incompatibility with the final histopathological or clinical diagnosis was observed in 7 patients $(0.54 \%)$. Three patients who were initially in category-II were diagnosed with pancreatic adenocarcinoma via histopathological examination of metastatic tissue, and one patient in category-III was regarded as chronic pancreatitis in their clinical follow-up. One of the two patients with category IVb was diagnosed with high grade PANIN in whipple resection, and the other with pancreatic ductal adenocarcinoma (table-3). In addition, 2 patients in category IVb were diagnosed with pancreatic adenocarcinoma during clinical follow-up depending on clinical findings and presence of metastases.

When cytological diagnoses according to PSC-PS were compared with the final clinical and histopathological diagnoses in terms of malignancy, sensitivity was $96.9 \%$, specificity was $96.8 \%$, PPV was $98.9 \%$, NPV was $90.9 \%$, and diagnostic accuracy was $96.9 \%$. For the group where ROSE was not available, the diagnostic accuracy was $96 \%$, the sensitivity was $94.44 \%$, specificity $100 \%$, PPV $100 \%$, NPV $87.50 \%$; while diagnostic accuracy was $97.09 \%$, sensitivity $97.47 \%$, specificity $95.83 \%$, PPV 98.77\%, NPV 92\% in patients with ROSE. There was no significant difference in diagnostic accuracy between those with and without ROSE (p:0.078). In addition, when the final diagnoses were compared with the PSC-PC categories, diagnostic accuracy were higher if the lesion contained a solid component compared to pure cystic ones $(p<0.001)$.

\section{Discussion}

One of our aims in this study was to assess the amount of tissue acquisition and diagnostic accuracy by EUS-FNA biopsy in pancreatic lesions. The compatibility of EUS-FNA PBS-PS categories with final clinical diagnosis or histopathology was quite high and parallel to the literature [10]. Discordancy with final diagnoses was observed in 7 of 128 cases with EUS-FNA cytology. ROSE was not available for 3 of the 7 patients. In a 57-year-old male patient who showed clinical discordancy and whose cytology was given category-II (non-ROSE), dense lymphocytes and histiocytes and a small number of ductal epithelial cells in cytology materials were evaluated in favor of chronic pancreatitis and malignancy could not be excluded. The final diagnosis was accepted as malignancy during the clinical follow-up and patient received chemotherapy. Another 49-year-old male patient with category-II PBS-PS, cytology had degenerated epithelial cells. This patient had ROSE, however because of high clinical suspicion of malignancy, a second EUS-FNA biopsy was performed. The second biopsy resulted as category- $\mathrm{V}$ and the patient was treated as adenocarcinoma. 67year-old female was diagnosed as category-II instead of non-diagnostic category because of the observed, even if, small number of honeycomb epithelial cells. This patient with extensive metastases was diagnosed with pancreatobiliary adenocarcinoma by liver tru-cut biopsy. A 54-year-old male patient had a history of chronic pancreatitis and walled of necrosis, was diagnosed as category-III. It was interpreted as possible reactive findings due to the low number of atypical cells observed. Again, in the cytological materials of three patients-were diagnosed as category IVb- with discordant diagnosis, diffuse mucin, anisochoric, increased nucleus size, and atypical epithelial cells were present. The final diagnoses of these patients during follow-up were pancreatic cancer, high-grade PANIN, and pancreatic adenocarcinoma, and all were diagnosed pathologically with Whipple materials.

Studies have focused mainly on solid lesions of the pancreas and report conflicting results about the effect of ROSE on diagnostic accuracy [11]. To a lesser extent, ROSE for cystic lesions of the pancreas has not been shown to have a significant effect on diagnostic accuracy, and there are even some studies emphasizing that ROSE should not be performed on cystic lesions [12]. In this study, we showed that the availability of ROSE in case of solid lesions is associated with higher diagnostic ability and diagnostic accuracy than cystic lesions. Also, if a cystic lesion contained 
a solid component, diagnostic ability was positively affected compared to pure cystic ones. However, evaluation of pure cystic lesions in our study showed that ROSE had no effect on diagnostic ability. There are some data in the literature that the demographic characteristics of the patients and the location of the lesions in the pancreas do not affect ROSE [13]. Also; in this study, patient's age, size of the lesions, and distribution of the lesion did not differ with availability of ROSE.

Another purpose of our study was to evaluate the necessity of using ROSE. Since, the need for ROSE for adequate tissue acquisition with EUS-FNA biopsy still remains as one of the most discussed issues in practice. In centers where it is possible, ROSE can provide the additional material needed in difficult situations and thus provide suitable material for histological evaluation that will combine the benefits of cytology and histology. Iglesias-Garcia et al. showed that the presence of ROSE was associated with significantly fewer passes, fewer scant samples, higher diagnostic yield, and higher diagnostic accuracy for malignancy [13]. Furthermore, Klapman et al. compared the EUS-FNA cytology results obtained by the same endosonographer at two centers, with and without ROSE. The diagnostic yield (regarding malignancy) was higher when a cytopathologist was present ( $58 \%$ vs $41.5 \%$; P:0.006), with a lower number of inadequate tissue specimens ( $9 \%$ vs $20 \%$; P: 0.035) [14]. However, on the contrary, Wani et al. compared the diagnostic yield and proportion of inadequate specimens undergoing EUS-FNA of pancreatic masses with ( $\mathrm{n}: 121)$ and without $(\mathrm{n}$ : 120) ROSE. There was no difference between groups in the diagnostic yield regarding malignancy (with ROSE 75.2\% vs without ROSE 71.7\%; P: 0.53) and proportion of inadequate specimens (9.9\% vs 13.3\%; P:0.4). Procedures with ROSE had significantly lower numbers of passes ( 3.7 vs 7 ; $P<0.001)$. There were no significant differences between groups with regard to overall procedure time, adverse events, number of repeat procedures, and cytologic characteristics of specimens [15]. Wani et al. in another review stated that, the use of ROSE does not impact the diagnostic yield for malignancy and the number of inadequate specimens, based on the available evidence. Therefore, they recommended that ROSE should be used in centers that have difficulty in achieving tissue adequacy [16].

In this respect, the necessity of ROSE procedure is still controversial [4]. Some large centers do not use ROSE due to loss of time, human resources and workforce; but some studies continue to emphasize the superiority of ROSE [3,5]. The diagnostic accuracy of EUS-guided tissue acquisition under ROSE is reported to be higher than $90 \%$ in most studies; however, comparable results have also been reported from some trials without ROSE [13,17]. In one recent meta-analysis, authors found that there was no indication that the application of ROSE improved the diagnostic yield (risk difference [RD], $0.04 ; 95 \% \mathrm{Cl}, 0.05$ to 0.13 ) [18]. In addition to these discussions, in this study, it was shown that ROSE had a significant advantage over the non-ROSE in 128 cases with diagnostic results in the first EUS-FNA biopsies. However, although the ROSE procedure was found to be significant in terms of yielding diagnostic results, the final diagnostic accuracy of the cases with ROSE was not significantly different from those without ROSE.

Lisotti A. et al. in their study, when EUS-FNA biopsy diagnoses and final diagnostic results were compared in cases with and without ROSE; performing with ROSE had a higher pooled sensitivity with similar pooled specificity; in particular, sensitivity and specificity were 83\% (95\% Cl, 64\%-93\%) and 98\% (95\% Cl, 80\%-100\%) when ROSE was present, respectively, as compared with $65 \%(95 \% \mathrm{Cl}), 57 \%-73 \%)$ and $94 \%(95 \% \mathrm{Cl}, 31 \%-100 \%)$ when ROSE was not available [7]. However, Fabbri et al. in his study, when 333 pancreatic solid lesions were divided into ROSE and non-ROSE, no significant difference in sensitivity, specificity, positive and negative likelihood ratios, and diagnostic accuracy was found between the two study groups [11]. In addition, some studies have shown that ROSE's success in providing diagnostic results is insufficient even if it is applied in non-diagnostic cases [17]. In our study, in 34 non-diagnostic cases, no significant difference was observed in the success of acquiring final diagnostic results between those who underwent ROSE and those who didn't. 
Tissue acquisition with ROSE can also contribute to the pathologist in terms of the number of passes, slide smearing and cell blocks. In this study, the amount of tissue acquired with ROSE (number of slides, cell blocks) was found to be significantly superior than those without ROSE. The reason for this may be the intervention of the cytopathologist/ pathologist/ cytology technician who qualifies the cytological material that is insufficient during ROSE, increasing the number of passes and the manipulation for obtaining tissue, also spreading the tissue to the slides and forming the appropriate cell block. The advantages of obtaining a cell block, especially with fine needle aspiration, are being able to see the lesion pattern, performing immunohistochemical staining to support the diagnosis, and acquirement of tissue for molecular analysis, even contributing to the chemotherapy regimen and molecular target therapy [19].

Studies report that the needle type used and macroscopic on-site evaluation by the endoscopist increase the quality and tissue acquisition and thus success in acquiring cell block [20]. Although white, yellowish-colored biopsy material of appropriate thickness helps to acquire more cells and to show the pattern and architecture of the lesion, the effect of making a slide smear in excluding differential diagnoses and reaching a definitive diagnosis cannot be ignored $[4,13,21]$. Adequate slide number and presence of cell block may be sufficient to make a definitive diagnosis without the need for a second interventional procedure. In addition, it is very critical for the patient that the cell block can provide the tissue for auxiliary immunohistochemical techniques and molecular tests [22].

There are studies in the literature to optimize the effectiveness of needle type, number of passes, smearing slide techniques and cell block acquisition in ROSE $[5,6]$. Erickson et al. in their study, stated that the number of passes should be between 3 and 6 in order to obtain high diagnostic accuracy with ROSE during the FNA procedure to the pancreas [6]. Furthermore, Chung et al. in their multicenter study, they suggested 4 as the optimum number of passes to be applied in centers that do not use ROSE in Korea [5]. Mizutani et al. demonstrated the contribution of the cell block acquirement in their study to make the definitive diagnosis, in terms of the applicability of ancillary tests and molecular studies [19]. Therefore, even a single cell block from the lesion can be very valuable, increasing the sensitivity and specificity for accurate diagnosis. In addition to all these, although there are studies on the optimization of the obtained cytological material with the slide smear technique, but, the optimum "number of slide smearing" requiring for a diagnostic ability has not been sufficiently examined in the literature for both ROSE and non-ROSE applications.

In our study, the application of ROSE in diagnostic cases was significantly higher than those who didn't have ROSE in terms of the number of passes, slides, and cell blocks. However, in cases with ROSE, the diagnostic cases was not different than non-diagnostic ones regarding the number of passes, slides and cell blocks. ROSE was independently associated with diagnostic ability in regression analysis, which can be interpreted as follows: 1) Although there is a pathologist at the bedside, it may not have sufficiently increased the number of passes and thus the tissue acquisition in non-diagnostic cases. In addition, 2) slides and cell blocks may have been prepared technically improperly, and it may have caused degeneration of cells and tissues with artefactual changes. This could have prevented giving diagnostic competence. 3) If the possibility of complications is high in patients who have undergone intervention, the number of passes may be reduced.

\section{Conclusion}

As a result, ROSE can increase the number of passes, slides and cell blocks, but it does not have an advantage in diagnostic accuracy. The optimum number of slides has not been examined in the literature, and ROSE may increase the number of required slide smears, which may benefit the pathologist in diagnosis. If the lesion is solid and/or contains a solid component, the success of obtaining a diagnostic ability is higher in patients with ROSE than in those 
without. Therefore, ROSE still maintains its applicability in terms of making the final diagnosis to the patient and increasing the diagnostic efficiency.

\section{Abbreviations}

ROSE: rapid on-site evaluation

EUS: endosonographic ultrasound imaging

FNA: fine needle aspiration

PSC-PS: Papanicolaou Society of Cytopathology in Pancreatobiliary System

PPV: positive predictive value

NPV: negative predictive value

SD: standard deviation

IQR: interquartile range

PANIN: high grade pancreatic intraepithelial neoplasia

IPMN: intraductal papillary mucinous neoplasm

WON: walled of necrosis

NA: not available

T: true

F: false

\section{Declarations}

\section{Funding}

There is no funding for this research.

\section{Author information}

Affiliations

Health Sciences University, Umraniye Education and Research Hospital, Pathology Department, Umraniye/Istanbul Address: Alemdağ Bulvarı, Elmalıkent Mahallesi, Posta kodu:34766, Umraniye Eğitim ve Araştırma Hastanesi, Ümraniye-Istanbul/Türkiye

Irem Guvendir, Itir Ebru Zemheri

Health Sciences University Umraniye Training and Research Hospital, Gastroenterology Department, Umraniye/Istanbul 
Address: Alemdağ Bulvarı, Elmalıkent Mahallesi, Posta kodu:34766, Umraniye Eğitim ve Araştırma Hastanesi, Ümraniye-i̇stanbul/Türkiye

Kamil Ozdil

\section{Contributions}

Concepts and design: Irem Guvendir. Definition of intellectual content: Itir Ebru Zemheri. Literature search,:Irem Guvendir, Itir Ebru Zemheri, Kamil Ozdil. Manuscript preparation: Irem Guvendir, Itir Ebru Zemheri. Manuscript editing: Irem Guvendir, Itir Ebru Zemheri, Kamil Ozdil. Manuscript review: Irem Guvendir, Itir Ebru Zemheri, Kamil Ozdil

All authors read and approved the final manuscript.

\section{Corresponding author}

Correspondence to Irem Guvendir.

\section{Ethics declarations}

\section{Competing interests}

The authors declare that they have no competing interests.

\section{References}

1. McGuigan, A., Kelly, P., Turkington, R. C., Jones, C., Coleman, H. G., \& McCain, R. S. (2018). Pancreatic cancer: A review of clinical diagnosis, epidemiology, treatment and outcomes. World Journal of Gastroenterology, 24(43), 4846-4861. doi:10.3748/wjg.v24.i43.4846

2. Ilic M, Ilic I. Epidemiology of pancreatic cancer. World J Gastroenterol. 2016;22:9694-9705 doi: 10.3748/wjg.v22.i44.9694.

3. Pitman, M., Centeno, B., Genevay, M., Stelow, E., Mino-Kenudson, M., Schmidt, C. M., ... Brugge, W. (2014). Standardized terminology and nomenclature for pancreatobiliary cytology: The Papanicolaou Society of Cytopathology Guidelines. CytoJournal, 11(2), 15. doi:10.4103/1742-6413.133343

4. Crinò, S. F., Manfrin, E., Scarpa, A., Baldaque-Silva, F., Carrara, S., De Nucci, G., ... Larghi, A. (2019). EUS-FNB with or without on-site evaluation for the diagnosis of solid pancreatic lesions (FROSENOR): Protocol for a multicenter randomized non-inferiority trial. Digestive and Liver Disease. doi:10.1016/j.dld.2019.03.008

5. Chung MJ, Park SW, Kim SH, Cho CM, Choi JH, Choi EK, Lee TH, Cho E, Lee JK, Song TJ, Lee JM, Son JH, Park JS, Oh CH, Park DA, Byeon JS, Lee ST, Kim HG, Chun HJ, Choi HS, Park CG, Cho JY.Clinical and Technical Guideline for Endoscopic Ultrasound (EUS)-Guided Tissue Acquisition of Pancreatic Solid Tumor: Korean Society of Gastrointestinal Endoscopy (KSGE). Clin Endosc. 2021 Mar;54(2):161-181. Epub 2021 Mar 24.PMID: 33761231 doi: 10.5946/ce.2021.069.

6. Erickson RA, Sayage-Rabie L, Beissner RS (2000) Factors predicting the number of EUS-guided fine-needle passes for diagnosis of pancreatic malignancies. Gastrointest Endosc 51: 184-190 doi: 10.1016/s0016-5107(00)704160 . 
7. Lisotti, A., Frazzoni, L., Fuccio, L., Serrani, M., Cominardi, A., Bazzoli, F., \& Fusaroli, P. (2020). Repeated EUS-FNA of pancreatic masses after nondiagnostic or inconclusive results: systematic review and meta-analysis.

Gastrointestinal Endoscopy. doi:10.1016/j.gie.2020.01.034

8. Lewin, D. (2020). Optimal EUS-guided FNA cytology preparation when rapid on-site evaluation is not available. Gastrointestinal Endoscopy, 91(4), 847-848. doi:10.1016/j.gie.2019.12.009

9. Hoda, R. S., Finer, E. B., Arpin, R. N., Rosenbaum, M., \& Pitman, M. B. (2019). Risk of Malignancy in the Categories of The Papanicolaou Society of Cytopathology System for Reporting Pancreaticobiliary Cytology. Journal of the American Society of Cytopathology. doi:10.1016/j.jasc.2019.01.002

10. Ozretić, L., Simonović, A. V., Rathbone, M. L., Young, M. P. A., \& Perez-Machado, M. A. (2021). The benefits of the Papanicolaou Society of Cytopathology System for reporting pancreatobiliary cytology: A 2-year review from a single academic institution. Cytopathology, 32(2), 227-232. doi:10.1111/cyt.12949

11. Fabbri, C., Fuccio, L., Fornelli, A., Antonini, F., Liotta, R., Frazzoni, L., ... Tarantino, I. (2016). The presence of rapid onsite evaluation did not increase the adequacy and diagnostic accuracy of endoscopic ultrasound-guided tissue acquisition of solid pancreatic lesions with core needle. Surgical Endoscopy, 31(1), 225-230. doi:10.1007/s00464016-4960-4

12. Estrada, P., Benson, M., Gopal, D., Buehler, D., \& Pfau, P. (2019). Cytology with rapid on-site examination (ROSE) does not improve diagnostic yield of EUS-FNA of pancreatic cystic lesions. Diagnostic Cytopathology. doi:10.1002/dc.24291

13. Iglesias-Garcia, J., Dominguez-Munoz, J. E., Abdulkader, I., Larino-Noia, J., Eugenyeva, E., Lozano-Leon, A., \& Forteza-Vila, J. (2011). Influence of On-Site Cytopathology Evaluation on the Diagnostic Accuracy of Endoscopic Ultrasound-Guided Fine Needle Aspiration (EUS-FNA) of Solid Pancreatic Masses. The American Journal of Gastroenterology, 106(9), 1705-1710. doi:10.1038/ajg.2011.119

14. Klapman JB, Logrono R, Dye CE, et al. Clinical impact of on-site cytopathology interpretation on endoscopic ultrasound-guided fine needle aspiration. Am J Gastroenterol 2003;98:1289-94 doi: 10.1111/j.1572-

0241.2003.07472.x.

15. Wani S, Mullady D, Early D, et al. The clinical impact of immediate onsite cytopathology evaluation during endoscopic ultrasound-guided fine needle aspiration (EUS-FNA) of pancreatic mass: final results of a multicenter, prospective randomized controlled trial. Gastrointest Endosc 2014;79:AB192-3. doi: 10.1038/ajg.2015.262. Epub 2015 Sep 8.

16. Sachin Wani 1, V Raman Muthusamy 2, Srinadh Komanduri 3 EUS-guided tissue acquisition: an evidence-based approach (with videos) Review Gastrointest Endosc. 2014 Dec;80(6):939-59.e7. doi: 10.1016/j.gie.2014.07.066.

17. Cermak, T. S., Wang, B., DeBrito, P., Carroll, J., Haddad, N., \& Sidawy, M. K. (2012). Does on-site adequacy evaluation reduce the nondiagnostic rate in endoscopic ultrasound-guided fine-needle aspiration of pancreatic lesions? Cancer Cytopathology, 120(5), 319-325. doi:10.1002/cncy.21201

18. Kong F, Zhu J, Kong X, et al. Rapid on-site evaluation does not improve endoscopic ultrasound-guided fine needle aspiration adequacy in pancreatic masses: a meta-analysis and systematic review. PLoS One 2016;11:e0163056 doi: 10.1371/journal.pone.0163056. eCollection 2016.

19. Mizutani N, Mochizuki M, Toki M. Assessment of preoperative pancreatic biopsy, cytological/histological review of cell-block-specimens obtained by endoscopic ultrasound-guided fine-needle aspiration: Laboratory-based study. Diagnostic Cytopathology. 2020;48:408-413. doi: 10.1002/dc.24358.

20. Leung Ki, E.-L., Lemaistre, A.-I., Fumex, F., Gincul, R., Lefort, C., Lepilliez, V., ... Napoléon, B. (2019). Macroscopic onsite evaluation using endoscopic ultrasound fine needle biopsy as an alternative to rapid onsite evaluation. Endoscopy International Open, 07(02), E189-E194. doi:10.1055/a-0770-2726

Page $10 / 14$ 
21. Iwashita, T., Yasuda, I., Mukai, T., Doi, S., Nakashima, M., Uemura, S., ... Moriwaki, H. (2015). Macroscopic on-site quality evaluation of biopsy specimens to improve the diagnostic accuracy during EUS-guided FNA using a 19gauge needle for solid lesions: a single-center prospective pilot study (MOSE study). Gastrointestinal Endoscopy, 81(1), 177-185. doi:10.1016/j.gie.2014.08.040

22. Ieni, A., Todaro, P., Crinò, S. F., Barresi, V., \& Tuccari, G. (2015). Endoscopic ultrasound-guided fine-needle aspiration cytology in pancreaticobiliary carcinomas: diagnostic efficacy of cell-block immunocytochemistry. Hepatobiliary \& Pancreatic Diseases International, 14(3), 305-312. doi: 10.1016/s1499-3872(15)60367-8.

\section{Tables}

\section{Table 1}

Comparison of patients with/without ROSE by using passes of needles, slides and cell blocks.

\begin{tabular}{|llll|}
\hline Number of & Patients with ROSE(n:121) & Patients without ROSE(n:41) & $p$ \\
\hline Passes of needles & & & 0.004 \\
(mean-median & $1.79-2$ & $1.37-1$ & \\
min-max) & $1-5$ & $1-6$ & 0.001 \\
Number of Slides & & & \\
(mean-median & $9.9-9$ & $7.3-8$ & \\
min-max) & $1-27$ & $0-31$ & $<0.001$ \\
Number of Cell blocks & & & \\
(mean-median & $2.1-2$ & $0.8-1$ & \\
min-max) & $0-6$ & $0-5$ & \\
\hline
\end{tabular}

Table 2

Distribution of the cases according to Papanicolaou Society of Cytopathology for Pancreatobiliary System (PSC-PS) 


\begin{tabular}{|llll|}
\hline PSC-PS CATEGORY & $\mathrm{n:162}$ & $\begin{array}{l}\text { Biopsy or surgery } \\
\text { procedure } \\
\text { (n:26) }\end{array}$ & $\begin{array}{l}\text { Concordance with definite histopathological or } \\
\text { clinical diagnosis }\end{array}$ \\
\hline I (non diagnostic) & $34(20 \%)$ & 9 & 21 malignant \\
& & & 13 benign \\
\hline II (benign) & $30(18.5 \%)$ & 3 & $\% 93.3$ (3 of them false negative) \\
\hline III (atypical) & $18(11 \%)$ & 4 & $\% 94.4$ (1 of them false positive) \\
\hline IVa (neoplastic:benign) & $3(0.18 \%)$ & 0 & $\begin{array}{l}\% 80 \\
\text { concordant) * }\end{array}$ \\
\hline IVb (neoplastic:other) & $10(0.61)$ & 4 & $\% 100$ \\
\hline $\begin{array}{l}\text { V (suspicious for } \\
\text { malignancy) }\end{array}$ & $11(0.67 \%)$ & 2 & $\% 100$ \\
\hline $\begin{array}{l}\text { VI (malignant) } \\
\text { *One had high grade PANIN, one had ductal adenocarcinoma in their whipple procedures. The other patient had } \\
\text { accepted as pancreatic adenocarcinoma due to clinical follow ups }\end{array}$ \\
\hline
\end{tabular}

Table 3

Cases which have definitive histopathological diagnosis. 


\begin{tabular}{|c|c|c|c|c|c|c|c|c|c|}
\hline No & Sex & Age & Location & $\mathrm{S} / \mathrm{C}$ & $\begin{array}{l}\text { Size } \\
(\mathrm{mm})\end{array}$ & $\begin{array}{l}\text { PSC- } \\
\text { PS }\end{array}$ & $\begin{array}{l}\text { Histopathology } \\
\text { Specimen }\end{array}$ & $\begin{array}{l}\text { Histopathology } \\
\text { Diagnosis }\end{array}$ & Concordance \\
\hline 1 & $\mathrm{~F}$ & 67 & Head & C & 28 & I & Tru-cut & Panc. Adeno Ca. & NA \\
\hline 2 & $\mathrm{~F}$ & 62 & Body & C & 12 & I & Tru-cut & Panc. Adeno Ca & NA \\
\hline 3 & M & 74 & Tail & C & 18 & 1 & Sub.pancreatectomy & Panc. Adeno Ca & NA \\
\hline 4 & M & 57 & Tail & C & 16 & I & Tru-cut & Panc. Adeno Ca. & NA \\
\hline 5 & $\mathrm{~F}$ & 32 & Tail & C & 36 & 1 & Whipple & $\begin{array}{l}\text { Mucinous cystic } \\
\text { neplasia }\end{array}$ & NA \\
\hline 6 & $\mathrm{~K}$ & 61 & Head & C & 8 & I & Whipple & Panc. Adeno Ca & NA \\
\hline 7 & $E$ & 68 & Body & C & 59 & I & Tru-cut & Panc. Adeno Ca & NA \\
\hline 8 & $\mathrm{~F}$ & 33 & Tail & C & 48 & I & $\begin{array}{l}\text { Distal } \\
\text { Pancreatectomy }\end{array}$ & $\begin{array}{l}\text { Mucinous Cystic } \\
\text { Neoplasia }\end{array}$ & NA \\
\hline 9 & M & 57 & Tail & S & 19 & I & Whipple & $\begin{array}{l}\text { Chronic } \\
\text { Pancreatitis }\end{array}$ & $\mathrm{T}$ \\
\hline 10 & M & 65 & Head & S & 25 & II & Whipple & $\begin{array}{l}\text { Chronic } \\
\text { Pancreatitis }\end{array}$ & $\mathrm{T}$ \\
\hline 11 & M & 57 & Head & C & 55 & II & Tru-cut & $\begin{array}{l}\text { Chronic } \\
\text { Pancreatitis }\end{array}$ & $\mathrm{T}$ \\
\hline 12 & $\mathrm{~F}$ & 54 & Tail & S & 30 & II & Whipple & WON & $\mathrm{T}$ \\
\hline 13 & M & 55 & Head & S & 50 & III & Tru-cut & Panc. Adeno Ca & $\mathrm{T}$ \\
\hline 14 & M & 73 & Uncinate & C & 35 & III & Whipple & Panc. Adeno Ca & $\mathrm{T}$ \\
\hline 15 & M & 54 & Head & S & 64 & III & Tru-cut & $\begin{array}{l}\text { Follicular } \\
\text { Lymphoma(G3b) }\end{array}$ & $\mathrm{T}$ \\
\hline 16 & M & 65 & Body & S & 16 & III & Whipple & Panc. Adeno Ca & $\mathrm{T}$ \\
\hline 17 & M & 64 & Uncinate & S & 45 & III & Whipple & $\begin{array}{l}\text { Neuroendocrine } \\
\text { Tumor(G3) }\end{array}$ & $\mathrm{T}$ \\
\hline 18 & M & 28 & Head & S & 20 & III & Excision & $\begin{array}{l}\text { Mixed Acinar } \\
\text { Neuroendocrine } \\
\text { Ductal } \\
\text { Neoplasia }\end{array}$ & $\mathrm{T}$ \\
\hline 19 & M & 49 & Uncinate & C & 32 & VI & Whipple & Panc. Adeno Ca & $\mathrm{T}$ \\
\hline 20 & $\mathrm{~F}$ & 74 & Head & S & 28 & VI & Whipple & Panc Adeno Ca. & $\mathrm{T}$ \\
\hline 21 & $\mathrm{~F}$ & 72 & Head & C & 32 & VI & Whipple & Panc Adeno Ca. & $\mathrm{T}$ \\
\hline 22 & M & 65 & Tail & C & 43 & VI & Sub Pancreatectomy & $\begin{array}{l}\text { Ductal Adeno } \\
\text { Ca. }\end{array}$ & $\mathrm{T}$ \\
\hline 23 & M & 38 & Head & S & 27 & $\mathrm{IVb}$ & Whipple & $\begin{array}{l}\text { High Grade } \\
\text { PANIN }\end{array}$ & $\mathrm{F}$ \\
\hline 24 & M & 37 & Head & C & 16 & $\mathrm{IVb}$ & Whipple & IPMN & $\mathrm{T}$ \\
\hline 25 & M & 52 & Tail & S & 40 & $\mathrm{IVb}$ & Whipple & $\begin{array}{l}\text { Neuroendocrine } \\
\text { Tumor(G1) }\end{array}$ & $\mathrm{T}$ \\
\hline
\end{tabular}


26 M 66 Head $\quad$ S $22 \quad$ IVb $\quad$ Whipple $\quad$ Ductal Adeno $\quad F$

S: solid, C: cystic, PSC-PS: Papanicolaou Society of Cytology in Pancreatobiliary System, NA: not available, T: true, F: false, WON: Walled of pancreatic necrosis 